\title{
Effect of patellofemoral joint targeted education, and exercise guidelines on outcomes of patients with patellofemoral osteoarthritis
}

\author{
Ghada H. Ahmed ${ }^{1}$, Sahar A. Abd-Elmohsen*1, Shimaa H. Mohamed ${ }^{1}$, Hesham Abd EL-Rahim Elkady ${ }^{2}$, Eman A.M. \\ Alkady $^{2}$ \\ ${ }^{1}$ Medical Surgical Nursing Department, Faculty of Nursing, Asyut University, Egypt \\ ${ }^{2}$ Faculty of Medicine, Asyut University, Egypt
}

Received: June 1, 2020

Accepted: June 27, 2020

Online Published: July 20, 2020

DOI: 10.5430/jnep.v10n10p101

URL: https://doi.org/10.5430/jnep.v10n10p101

\begin{abstract}
Background and objective: Patellofemoral joint osteoarthritis (PFJOA) is an under recognized category of arthritis, evident in almost $70 \%$ of adults with knee pain. Objective was to evaluate the effect of patellofemoral joint targeted education, and exercise guidelines on outcomes of patients with patellofemoral osteoarthritis.

Methods: A quasi experimental (pre/post) design was used. Setting: The study was conducted in the physiotherapy department of a large University Hospital in Egypt. Sample: A randomized 30 adult patients with symptomatic and diagnosed PFJOA. Researchers and Physiotherapists delivered the PFJ-targeted education, and exercise program in 3 sessions over 9 month period. Results: The PFJ-targeted education, and exercise guidelines resulted in a highly statistically significant difference in the Knee Injury and Osteoarthritis Outcome Score (KOOS) pre/posttest in the whole five domains of the questionnaire; Pain (nine items); Symptoms (seven items); ADL Function (17 items); Sport and Recreation Function (five items); and Quality of Life (four items) $p<.001 * *$.

Conclusions: PFJ-targeted education, and exercise guidelines were more effective in reducing pain, improving physical function, and activities of daily living. Recommendation: Replication of the study using a larger probability sample from different geographical areas to help for generalization of the results.
\end{abstract}

Key Words: PFJ-targeted education, Exercise guidelines, Patellofemoral osteoarthritis, Patients' outcomes

\section{INTRODUCTION}

Patellofemoral joint osteoarthritis (PFJOA) is common and leads to pain and disability. The PFJ is involved in about $65 \%$ of patients with knee osteoarthritis (OA); especially within the lateral patellofemoral compartment. ${ }^{[1]}$ PFJOA is evident in nearly $70 \%$ of adults with knee pain. ${ }^{[2-5]}$

Global statistics revealed that more than 100 million peo- ple all over the world suffer from OA, which is considered one of the most common causes of disability. While OA affects men and women equally, it is more common among men younger than 45 years and women older than 45 years. Unfortunately, the majority of those suffering from OA are deprived of access to quality treatment. ${ }^{[6]}$

In knee $\mathrm{OA}$ almost little consideration has been given to the

\footnotetext{
*Correspondence: Sahar A. Abd-Elmohsen; Email: sara.saleh17@yahoo.com; Address: Medical Surgical Nursing Department, Faculty of Nursing, Asyut University, Egypt.
}

Published by Sciedu Press 
PFJ, although researchers have suggested that disease in the PF compartment may be strongly associated with disability of the lower extremity. Knee pain in OA is more correlated in cases of involvement of the PF joint than in the isolated involvement of the tibiofemoral (TF) joint. ${ }^{[7]}$

PFJOA has no distinct symptoms although anterior knee pain is the commonest patients' complaint. The pain is provoked by ascending and descending stairs, climbing hill, standing from a seated position, kneeling or squatting, which is related to friction. Few patients complain of knee stiffness or pseudo-locking resulting from "kissing" lesions between the patella and the trochlea groove when friction occurs between the exposed bones. ${ }^{[8]}$

Exercise programs comprise more dynamic exercises and need the performance of activities which are normally limited by knee OA patients, as ascending and descending stair, walking, and chair stands; although these trials have shown better outcomes for pain, physical function, and QOL. The most common types of exercises include; ankle plantar flexion/dorsiflexion, isometric knee extension in outer range, knee extension/flexion using a pillow behind the knee, knee and hip flexion/extension, isometric buttock contraction, hip abduction/adduction and straight leg raise. ${ }^{[9]}$

Physiotherapy is a harmless, and economical conventional intervention, which foster physical activity and selfmanagement through exercise. ${ }^{[10]}$ Exercise is one of the most important and controversial non pharmacologic management approaches for knee OA. Health care providers and patients share varied and commonly pseudoscientific beliefs about the effects of exercise on knee OA. ${ }^{[11]}$

Obesity and inactivity as risk factors for OA are excellent targets for rehabilitation that can be changed using diet and exercise. The range of rehabilitation includes conservative methods to improve or restore physical ability and quality of life. The effectiveness of exercise and diet in management of OA is well established. ${ }^{[12-15]}$

\subsection{Operational definition}

The patient outcomes (pain and physical function) of patients with patellofemoral osteoarthritis.

\subsection{Significance of the study}

Through a period of several years of experience in student training in the orthopedic department at Asyut University Hospital the researcher observed that these patients need special exercise guidelines to improve activities of daily living. This study will help such group of patients have fewer complications and improve their outcomes.

102

\subsection{Objective}

To evaluate the effect of patellofemoral joint targeted education, and exercise guidelines on outcomes of patients with patellofemoral osteoarthritis

\subsection{Research hypothesis}

Patients will have better outcomes post application of the guidelines.

\section{Patients and methods}

\subsection{Study design}

A quasi-experimental (pre/post) design was used.

\subsection{Setting}

The study was conducted in the Physiotherapy Department of a large University Hospital in Egypt.

\subsection{Sample}

A total of 30 adult patients diagnosed with patellofemoral osteoarthritis were included with the following criteria: age between 18-65 years; both male and female; through six months of follow up period.

\subsection{Exclusion criteria}

Other types of osteoarthritis.

\subsection{Tools}

Tool I: Structured Patient Interview Questionnaire:

It was based on the best available evidence and consists of two parts:

Part (A): Assessment of patient's demographic characteristics including age, gender, marital status and occupation.

Part (B): Assessment of patient's medical data including duration of patellofemoral osteoarthritis and affected side.

Tool II: The Knee Injury and Osteoarthritis Outcome Score (KOOS):

It is a self-administered knee-specific tool designed to assess short and long-term patient-relevant outcomes or consequences following knee injury which has been filled from the participants by the researchers in its original English language. It contains 42 items in 5 separately scored subscales; pain, symptoms, daily living activities, sport and recreational function, and knee-related QOL.

Scoring system: KOOS's dimensions are separately scored: Pain (9 items); Symptoms (7 items); ADL Function (17 items); Sport and Recreation Function (5 items); and Quality of Life (4 items). A five point Likert scale is used for scoring that range from zero representing no problems to $4=$ 
Extreme problems and each of the five scores is calculated as the sum of the items included. Scores are transformed on 0 to 100 scale (zero representing extreme knee problems and 100 representing no knee problems). ${ }^{[16]}$

The patellofemoral joint targeted education, and exercise guidelines:

This was prepared in a booklet by the researchers based on review of related literature in a simplified Arabic language and was supported by photo illustrations it contained items regarding the following; anatomical overview of the knee joint and function, predisposing risk factors and causes of patellofemoral osteoarthritis, manifestations, diagnosis, treatment (physiotherapy, conservative medical treatment and surgical treatment), nursing instructions for decreasing pain and improving physical function as avoidance of: standing for long periods and repetitive stair climbing, bending knee greater than 90 degrees, squatting. Maintain regular daily walking, weight reduction, the right way of getting up and down stairs, and exercises to improve knee function.

\subsection{Procedures}

-An approval from faculty of nursing ethical committee was taken. Hospital permission from the head of physiotherapy department was also taken after the aim and study nature were clarified. A literature review was done to prepare the study tool and patient guide from library and web sources. A pilot study was carried out during May 2019, on $10 \%$ of patients, in order to test clarity and applicability of the study tools; no changes were done in the tools, so that these patients were included in the main study.

-At first interview the researcher introduced herself to initiate line of communication, explained the nature \& purpose of the study and filled out the structured patient interview questionnaire sheet. The patellofemoral joint targeted education, and exercise guidelines have been implemented for all patients, the researcher explained to the patient the content of the booklet in the following sequence:

- The booklet content was delivered in three sessions; the duration of each was about 45 minutes, including 15 minutes for discussion and feedback.

- The researcher in the first session explained to the patient simple information about anatomical overview of the knee joint and function, predisposing risk factors and causes of patellofemoral osteoarthritis, manifestations, diagnosis and management.

- The second and third sessions were specified for exercise which was demonstrated by the researcher to the patient.

- Each patient obtained a copy of the booklet.

- The researcher met with each patient individually, the study and its aim were explained to the patient.

-Patients were assessed before receiving the booklet and six months after receiving the booklet through the follow up period, patients were conducted weekly by the researchers through telephone to make sure they are following the guidelines and to answer any questions that might arise.

-This study was carried out through the period from March 2019 to December 2019 at morning shift.

\subsection{Sample size}

The sample size was estimated after the pilot study conduction using the difference between pre and post group using knee related quality of life as primary outcome with a $p$ value $<.05$ and power analysis $80 \%$, confidence level 95 . The minimum sample size was 20 patients. However, 30 patients were included in this study work to avoid non-response rate.

\section{RESULTS}

Table 1 illustrates the socio-demographic characteristics of the studied sample; regarding age it ranges from 40 to 63 years with a mean \pm SD of $51.87 \pm 6.8,96.7 \%$ of them were female, $90 \%$ were married, and regarding occupation; $73.3 \%$ were housewives and $10 \%$ were employees, an equal percentage of them $(16.6 \%)$ were either left or right sided affected while $66.7 \%$ of them were having a bilateral affection, and for the duration of affection it ranges from (1-15 years) with a mean $\pm \mathrm{SD}$ of $5.43 \pm 4.07$.

Table 1. Distribution of the studied sample regarding their demographic and medical data $(\mathrm{n}=30)$

\begin{tabular}{lll}
\hline Variables & $\mathbf{N}$. & \% \\
\hline Age & & \\
Range & $40-63$ & \\
Mean \pm SD & $51.87 \pm 6.8$ & \\
Gender & & \\
Male & 1 & 3.3 \\
Female & 29 & 96.7 \\
Marital status & & \\
Married & 27 & 90.0 \\
Widow/widower & 3 & 10.0 \\
Occupation & & \\
Housewife & 22 & 73.3 \\
Employee & 8 & 26.7 \\
Affected side & & \\
Right side & 5 & 16.7 \\
Left side & 5 & 66.6 \\
Bilateral & 20 & \\
Duration of joint affection & & \\
Mean \pm SD & $5.43 \pm 4.07$ & \\
Range & $1-15$ years & \\
\hline
\end{tabular}


The appendix reflects distribution of the studied sample re- items; Sport \& Recreation Function = five items; Quality of garding KOOS pre/post application of the study, it shows a highly statistically significant difference in the score pre/posttest in the whole five domains of the questionnaire: Pain $=9$ items; Symptoms $=7$ items; ADL Function $=17$

Life $=$ four items.

Figure 1 shows a highly statistically significant difference pre/post application of the study in all items of the KOOS.

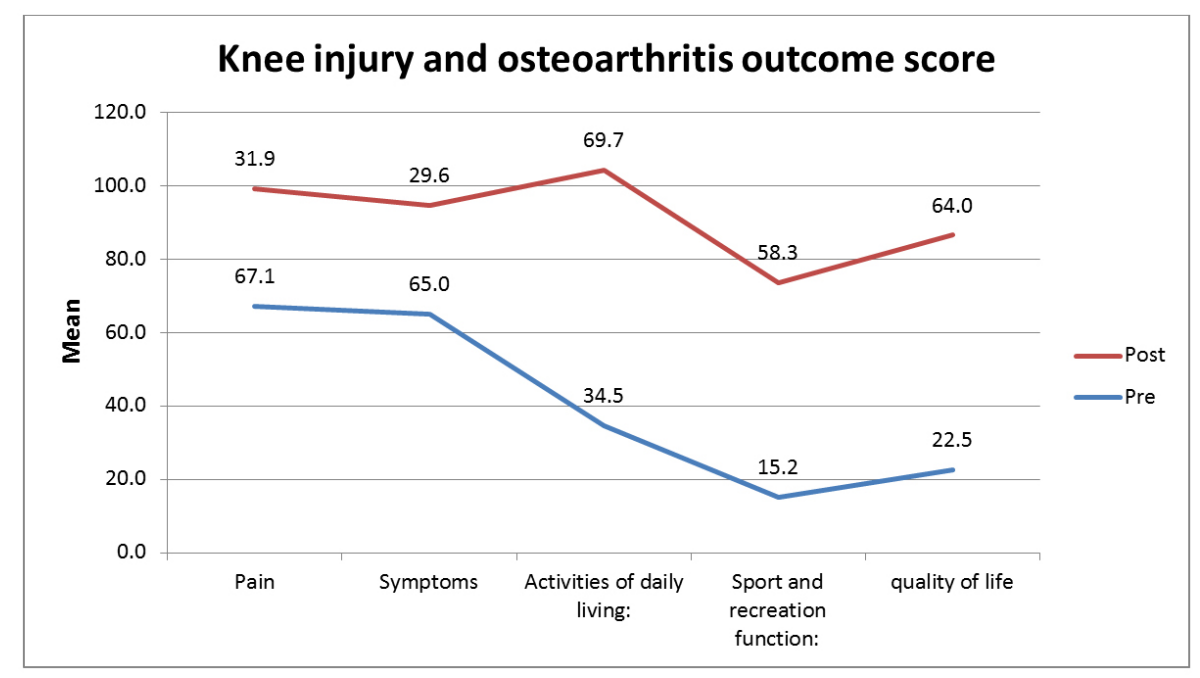

Figure 1. Pre/post study comparison regarding KOOS

Table 2 illustrates the relation between KOOS with the socio demographic data pre/post application of the study; it reveals that there was a highly statistically significant difference between age group and symptoms, and a statistically significant difference between age group and QOL pre application of the study ( $p$ value $=.002$ and .038 ) respectively, a statistically significant difference was found between occupation and symptoms ( $p$ value $=.021$ ), while there was no statistically significant difference between gender, occupation or affected side with any of the KOOS score pre/post application of the study.

Table 2. Relation between KOOS with Socio demographic data pre/post application of the study

\begin{tabular}{|c|c|c|c|c|c|c|c|c|c|c|c|}
\hline & & \multicolumn{5}{|l|}{ Pre } & \multicolumn{5}{|l|}{ Post } \\
\hline & & Pain & Symptoms & $\begin{array}{l}\text { Activities } \\
\text { of daily } \\
\text { living }\end{array}$ & $\begin{array}{l}\text { Sport and } \\
\text { recreation } \\
\text { function }\end{array}$ & $\begin{array}{l}\text { quality } \\
\text { of life }\end{array}$ & Pain & Symptoms & $\begin{array}{l}\text { Activities } \\
\text { of daily } \\
\text { living }\end{array}$ & $\begin{array}{l}\text { Sport and } \\
\text { recreation } \\
\text { function }\end{array}$ & $\begin{array}{l}\text { quality } \\
\text { of life }\end{array}$ \\
\hline \multirow{2}{*}{ Age } & $\mathrm{r}$ & -0.352 & $-.442-^{*}$ & 0.136 & 0.231 & 0.248 & -0.163 & 0.004 & -0.092 & 0.061 & 0.097 \\
\hline & $p$ & .056 & .014 & .472 & .219 & .187 & .389 & .983 & .630 & .750 & .611 \\
\hline \multirow{2}{*}{ Gender } & $\mathrm{r}$ & -0.292 & -0.152 & 0.301 & 0.261 & 0.315 & -0.271 & -0.272 & 0.269 & 0.316 & 0.279 \\
\hline & $p$ & .118 & .421 & .106 & .163 & .090 & .148 & .145 & .150 & .089 & .136 \\
\hline \multirow{2}{*}{ Marital } & $\mathrm{r}$ & 0.213 & 0.111 & -0.199 & -0.098 & -0.061 & -0.013 & 0.033 & -0.052 & -0.039 & 0.053 \\
\hline & $p$ & .258 & .560 & .291 & .608 & .751 & .946 & .864 & .787 & .838 & .779 \\
\hline \multirow{2}{*}{ Occupation } & $\mathrm{r}$ & 0.210 & $.429^{*}$ & -0.231 & -0.177 & -0.251 & 0.272 & 0.265 & -0.157 & -0.216 & -0.222 \\
\hline & $p$ & .264 & .018 & .219 & .350 & .181 & .145 & .156 & .406 & .251 & .239 \\
\hline \multirow{2}{*}{ side } & $\mathrm{r}$ & -0.155 & -0.341 & 0.332 & 0.330 & 0.088 & -0.162 & -0.253 & 0.167 & 0.341 & 0.059 \\
\hline & $p$ & .413 & .065 & .073 & .075 & .643 & .394 & .178 & .377 & .065 & .757 \\
\hline \multirow{2}{*}{ Duration } & $\mathrm{r}$ & 0.236 & -0.168 & -0.075 & -0.104 & 0.109 & 0.129 & -0.290 & 0.023 & 0.024 & 0.059 \\
\hline & $p$ & .210 & .376 & .693 & .585 & .567 & .498 & .120 & .903 & .900 & .755 \\
\hline
\end{tabular}

\section{Discussion}

Most PFJOA research focused on exercise therapy with less attention to patient education. So the current study focused on patient education which is a very crucial piece of treatment of patellofemoral osteoarthritis patients which is supported by the results of other researchers. ${ }^{[17]}$ 
Patient education is critical to treat patellofemoral pain (PFP) resulting from PFJOA. ${ }^{[17]}$ Esculier et al. ${ }^{[18]}$ conducted a randomized trial which focused attention on the importance of appropriate patient education in a running sample with PFP.

Effective patient education allows self-control and optimizes commitment to other interventions such as exercise therapy. Quality patient education should include; load and weight management when allowed by the orthopedic surgeon or physical therapist, understanding the possible worth of treatments such as exercise therapy and comprehending any fear of movement. ${ }^{[17]}$

Patient education must be individualized based on previous knowledge, needs and preferences, many education sessions may be needed to ease sufficient knowledge acquisition. ${ }^{[19]}$

Demographic characteristics of the studied sample revealed that the majority of patients were female; their age ranged from 40-63 years old. These study findings were supported by Ringdahl et al. ${ }^{[20]}$ and Magrans et al. ${ }^{[21]}$ who mentioned that knee $\mathrm{OA}$ is more prevalent between 30 and 65 years of age, affecting nearly $33.6 \%$ of people older than 65 years, with an incidence of 1 in 10 persons aging more than 65 years due to the nature and causes of OA. This fact is related to the drop in birth rates and the generally increasing life expectancy. There is frightening future increase in the prevalence of knee OA in elderly people.

In accordance with the current study results; many interventional studies including bracing, taping and exercise therapy reported improved knee health and quality of life. ${ }^{[22]}$

Similarly, Crossley et al. ${ }^{[23]}$ reported that exercises, PFJ targeted education, manual therapy and taping gave superior results for perceived change in patient's condition and pain, compared to physiotherapist delivered osteoarthritis education.
On the other hand, one randomized controlled trial reported that although notable improvements in pain and function, knee related quality of life did not improve more post physical therapy intervention plus education in comparison to education alone. It is possible that the KOOS quality of life subscale may not be sensitive to changes in knee pain and function. ${ }^{[24]}$

In the same line with the current study results, exercise was suggested for the treatment of knee OA by all present-day clinical guidelines. ${ }^{[25]}$

It was also clear in the systematic reviews which evaluated different outcomes the importance of exercise in knee OA patients for muscle strength and walking ability. ${ }^{[26,27]}$

Finally and in agreement with the current research results Esser \& Bailey ${ }^{[11]}$ reported that health care providers should include exercise guidance into clinical management and provide patients with reliable data and individualized exercise recommendations to help them manage the painful and frequently incapacitating symptoms of this disease.

\section{Conclusion}

Education and exercise guidelines were effective in reducing pain and improving patient's physical function.

\subsection{Limitation of the study}

The low number of cases included in the present study limiting generalization of the results.

\subsection{Recommendations}

Replication of the current research on a larger probability sample from different geographical areas to help for generalization of the results.

\section{CONFLICTS OF INTEREST Disclosure}

All authors declare no conflict of interest.

\section{REFERENCES}

[1] Hunter DJ, Harvey W, Gross KD, et al. A randomized trial of patellofemoral bracing for treatment of patellofemoral osteoarthritis. Osteoarthritis and Cartilage. 2011; 19: P792-800. PMid:21232620 https://doi.org/10.1016/j.joca.2010.12.010

[2] Duncan R, Hay E, Saklatvala J, et al. Prevalence of radiographic osteoarthritis: it all depends on your point of view. Rheumatology. 2006; 745-760.

[3] Kornaat PR, Bloem JL, Ceulemans RT, et al. Osteoarthritis of the knee: association between clinical features and MR imaging findings. Radiology. 2006; 239-811. PMid:16714463 https : //doi .org/10 $.1148 /$ radiol. 2393050253

[4] Szebenyi B, Hollander A, Dieppe P, et al. Associations between pain, function, and radiographic features in osteoarthritis of the knee. Arthritis Rheum. 2006; 5(4): 230-235. PMid:16385522 https : //doi.org/10.1002/art.21534

[5] Hinman RS, Bennel K, Metcalf B, et al. Patellofemoral osteoarthritis is common in middle-aged people with chronic patellofemoral pain. Arthritis Care Res. 2014; 1252-1257. PMid:24376057 https : //doi.org/10.1002/acr.22274

[6] Childs JD, Sparto PJ, Fitzgerald GK, et al. Alterations in lower extremity movement and muscle activation patterns in individuals with knee osteoarthritis. Clinical Biomechanics. 2004; 19(1): 44-49. PMid:14659929 https://doi.org/10.1016/j.clinbi omech.2003.08.007

[7] Duncan R, Peat G, Thomas E, et al. How do pain and function 
vary with compartmental distribution and severity of radiographic knee osteoarthritis? Rheumatology (Oxford). 2008; 1704-1707. PMid:18805874 https://doi.org/10.1093/rheumatology/k en339

[8] Young-Mo K, Yong BJ. Patellofemoral Osteoarthritis, Knee Surg. Relat Res. National Library of Medicine National Institutes of Health 2012; 24(4): 193-200. PMid:23269956 https://doi.org/10.5 792/ksrr. 2012.24.4.193

[9] Artz NE, Elvers KT, Lowe CM, et al. Effectiveness of physiotherapy exercise following total knee replacement: systematic review and meta-analysis. BMC Musculoskeletal Disorders. 2015; 16(1). PMid:25886975 https://doi.org/10.1186/s12891-015-046 9-6

[10] Ordan KM, Arden NK, Doherty M, et al. An evidence based approach to the management of knee osteoarthritis: Report of a Task Force of the Standing Committee for International Clinical Studies Including Therapeutic Trials. 2003; 62: 1145-1155. PMid:14644851 https://doi.org/10.1136/ard.2003.011742

[11] Esser S, Bailey A. Effects of exercise and physical activity on knee OA. Curr Pain Headache Rep. 2011; 15: 423-430. PMid:21956792 https://doi.org/10.1007/s11916-011-0225-z

[12] Messier S, Mihalko S, Legault C, et al. Effects of intensive diet and exercise on knee joint loads, inflammation, and clinical outcomes among overweight and obese adults with knee osteoarthritis. J Am Med Assoc. 2013; 310: 1263e73. PMid:24065013 https: //doi.org/10.1001/jama.2013.277669

[13] Fransen M, McConnell S, Harmer A, et al. Exercise for osteoarthritis of the knee. Cochrane Database Syst Rev. 2015.

[14] Hall M, Castelein B, Wittoek R, et al. Diet induced weight loss alone or combined with exercise in overweight or obese people with knee osteoarthritis: a systematic review and meta-analysis. Semin Arthritis Rheum. 2019; 48(5): 765e77. PMid:30072112 https://doi.org/10.1016/j.semarthrit.2018.06.005

[15] Verhagen AP, Ferreira M, Reijneveld-van de Vendel EA, et al. Do we need another trial on exercise in patients with knee osteoarthritis? No new trials on exercise in knee OA. Osteoarthr Cartil. 2019; 27(9): 1266e9. PMid:31220609 https : //doi.org/10.1016/j.joca. 2 019.04 .020

[16] Ewa MR, Stefan L. The Knee injury and Osteoarthritis Outcome Score (KOOS): from joint injury to osteoarthritis Health Qual Life Outcomes. 2003; 1: 64.

[17] Barton CJ, Lack S, Hemmings S, et al. The 'best practice guide to conservative management of patellofemoral pain': incorporating level 1 evidence with expert clinical reasoning. Br J Sports Med 2015; 49(14): 923-34. PMid:25716151 https://doi.org/10.1 136/bjsports-2014-093637
[18] Esculier JF, Bouyer LJ, Dubois B, et al. Is combining gait retraining or an exercise program with education better than education alone in treating runners with patellofemoral pain? A randomized clinical trial. Br J Sports Med. 2018; 52(10): 659-666. PMid:28476901 https ://doi.org/10.1136/bjsports-2016-096988

[19] Dobson F, Bennell KL, French SD, et al. Barriers and facilitators to exercise participation in people with hip and/or knee osteoarthritis: synthesis of the literature using behavior change theory. Am J Phys Med Rehabil. 2016; 95(5): 372-89.

[20] Ringdahl E, Pandit S. Treatment of knee osteoarthritis. Am Fam Physician. 2011; 83: 1287-1292

[21] Magrans CT, Wilborn C, Rasmussen C, et al. Effects of diet type and supplementation of glucosamine, chondroitin, and MSM on body composition, functional status, and markers of health in women with knee osteoarthritis initiating a resistance-based exercise and weight loss program. J Int Soc Sports Nutr. 2011; 8(1): 8. PMid:21689421 https://doi.org/10.1186/1550-2783-8-8

[22] Roos EM, Lohmander LS. The knee injury and osteoarthritis outcome score (KOOS): From joint injury to osteoarthritis. Health and Quality of Life Outcomes. 2003; 1(1): 64. PMid:14613558 https : //doi.org/10.1186/1477-7525-1-64

[23] Crossley KM, Vicenzino B, Lentzos J, et al. Exercise, education, manual-therapy and taping compared to education for patellofemoral osteoarthritis: a blinded, randomized clinical trial. Osteoarthritis Cartilage. 2015; 23(9): 1457-64. PMid:25960116 https ://doi.org/ $10.1016 / \mathrm{j} \cdot$ joca. 2015.04.024

[24] Coburn SL, Barton CJ, Filbay SR, et al. Quality of life in individuals with patellofemoral pain: A systematic review including meta-analysis. Phys Ther Sport. 2018; 33: 96-108. PMid:30059951 https://doi.org/10.1016/j.ptsp.2018.06.006

[25] Nelson AE, Allen KD, Golightly YM, et al. A systematic review of recommendations and guidelines for the management of osteoarthritis: the chronic osteoarthritis management initiative of the U.S. bone and joint initiative. Semin Arthritis Rheum. 2014; 701-712. PMid:24387819 https://doi.org/10.1016/j.semarthrit.2 013.11 .012

[26] Zacharias A, Green RA, Semciw AI, et al. Efficacy of rehabilitation programs for improving muscle strength in people with hip or knee osteoarthritis: a systematic review with meta-analysis. Osteoarthritis Cartilage. 2014; 22: 1752-1773. PMid:25065642 https://doi.org/10.1016/j.joca.2014.07.005

[27] Tanaka R, Ozawa J, Kito N, et al. Effects of exercise therapy on walking ability in individuals with knee osteoarthritis: a systematic review and meta-analysis of randomized controlled trials. Clin Rehabil. 2015; 30(1): 36-52. PMid:25691583 https://doi .org/10.1 $177 / 0269215515570098$ 